\title{
Growing evidence for benefits of minimally invasive radical cystectomy
}

\author{
Geraldine Pignot, Patrick Treacy, Jochen Walz \\ Department of Surgical Oncology, Institut Paoli-Calmettes, Marseille, France \\ Correspondence to: Geraldine Pignot. Department of Surgical Oncology, Institut Paoli-Calmettes, Marseille, France. Email: gg_pignot@yahoo.fr. \\ Comment on: Khan MS, Omar K, Ahmed K, et al. Long-term Oncological Outcomes from an Early Phase Randomised Controlled Three-arm Trial \\ of Open, Robotic, and Laparoscopic Radical Cystectomy (CORAL). Eur Urol 2020;77:110-8.
}

Submitted Apr 20, 2020. Accepted for publication May 29, 2020.

doi: $10.21037 /$ tau-20-873

View this article at: http://dx.doi.org/10.21037/tau-20-873

Although open radical cystectomy (ORC) is still regarded as the standard treatment for muscle-invasive bladder cancer, minimally invasive procedures are becoming more popular and increasingly performed. Laparoscopic surgery has inherent limitations and has been gradually supplanted by robot-assisted procedures, which have several advantages, including higher degree of freedom of movement and better ergonomics (1). Over the past decade, robot-assisted radical cystectomy (RARC) has gained attraction as an alternative to the conventional open approach, with a substantial increase in use over time, from $16.7 \%$ in 2010 to $25.3 \%$ in 2013 in the United States. However, installation and maintenance costs remain prohibitive and have drawn criticism. Thus, the question of the interest of RARC and its potential benefits for the patient is at the heart of current debates.

Khan et al. recently published an update from the English CORAL (Open, Laparoscopic and Robot Assisted Cystectomy) trial and present their results of the 5-year oncological outcomes (2). A total of 60 patients with either muscle-invasive bladder cancer $(\mathrm{n}=38)$ or high-risk non-muscle-invasive bladder cancer $(\mathrm{n}=21)$ were randomized into three groups: open $(\mathrm{ORC})$, laparoscopic (LRC) or robot-assisted cystectomy (RARC). This is a single institution experience with three expert surgeons beyond their learning curves.

The authors have previously published their perioperative outcomes and have already shown that mean operative time was significantly longer in RARC compared with ORC or LRC, while minimally invasive procedures were associated with reduced blood loss and less need for blood transfusions (3). Regarding the intraoperative outcomes, their results are in agreement with the literature. A systematic review and cumulative analysis of RARC in comparison with ORC and LRC have already shown that there was no significant difference in lymph node yield between RARC and ORC, while the performance of lymphadenectomy was correlated with surgeon and institutional volume (4). The CORAL trial confirms the feasibility of an adequate lymphadenectomy regardless of the surgical approach, since the median lymph node yield was 18.5 in ORC, 15.5 in LRC, and 14.5 in RARC.

Furthermore, positive surgical margins (PSM) rates did not differ significantly between the surgical arms (10\% in ORC, $5 \%$ in LRC, and $15 \%$ in RARC). It should be noted that these positive margins rates are quite high compared to those usually reported in the literature which are closer to $5 \%(5,6)$. This could probably be explained by the characteristics of the population since, among the 38 patients with muscle-invasive disease, only $6(15.8 \%)$ received neoadjuvant chemotherapy before cystectomy, resulting in $33.9 \%$ of $\mathrm{T} 3-\mathrm{T} 4$ stage $(52.6 \%$ of MIBC) and $25.4 \%$ of $\mathrm{N}+$ status (39.5\% of MIBC) on the final pathological specimen. However, in this cohort, none of the patients developed peritoneal metastasis or port site metastasis to suggest seeding from cell spillage due to an intraoperative tumor effraction. Other studies also confirm the absence of significant relationship between the surgical approach and PSM (4-7). The recently published RAZOR trial, comparing RARC versus ORC, found a higher incidence of positive bladder soft tissue margins in the robotic arm compared to the open arm, but the difference in overall positive margin rate between the two arms did not reach significance (8).

Oncological outcomes in terms of disease-free survival (DFS), cancer-specific survival (CSS), and overall survival 
(OS) have historically been widely debated and few series had a mean follow-up of more than 24 months. Even if the oncological results up to 5 years seemed to be similar to those reported for ORC, we were awaiting more definitive answers from longer-term prospective randomized trials. After a median follow-up of more than 5 years in the three arms, the CORAL trial showed no significant difference in RFS, CSS, and OS between the three surgical arms. The 5 -year RFS was $60 \%, 58 \%$, and $71 \%$; 5 -year CSS was $64 \%, 68 \%$, and $69 \%$; and 5 -year OS was $55 \%, 65 \%$, and $61 \%$ for ORC, RARC, and LRC, respectively (2). These survival rates $50 \%$ of patients recurred during followup, half locally and half metastatically) are in adequation with the characteristics of the patients given that the oncological outcomes largely depend on the local stage. The authors conclude that minimally invasive techniques achieved equivalent oncological outcomes to the gold standard of ORC. Due to the small sample size of this study, these results should be interpreted with caution. However, these findings are in agreement with those from other randomized controlled trials comparing RARC and ORC $(8,9)$. In the RAZOR non-inferiority trial $(n=302$ patients), the 2 -year progression-free survival was $72.3 \%$ in the robotic cystectomy group versus $71.6 \%$ in the open cystectomy group $(\mathrm{P}=0.001)$, indicating non-inferiority of robotic cystectomy (8). In the randomized trial of Bochner et al. ( $\mathrm{n}=118$ patients), no difference was observed in terms of recurrence, cancer-specific survival, or overall survival between ORC and RARC (9). However, the pattern of first recurrence demonstrated a non-statistically significant higher proportion of metastatic sites for those undergoing ORC $(\mathrm{P}=0.064)$ and a greater number of local/abdominal sites in the RARC-treated patients $(\mathrm{P}=0.035)$.

Although all surgical approaches appear to be equivalent in terms of long-term oncological results, the benefits of RARC over ORC remain unclear. The main expected benefit of minimally invasive approaches lies in reducing the morbidity of cystectomy knowing that radical cystectomy remains a highly morbid procedure. Regarding postoperative outcomes, data are controversial. Some studies suggest that minimally invasive surgery is associated with lower 30- and 90-day postoperative complications rates and a trend toward shorter length of stay (10-15). In the initial publication of the CORAL trial focused on postoperative outcomes, the 30-day complication rates varied significantly between the three arms (ORC: 70\%; RARC: 55\%; LRC: $26 \% ; \mathrm{P}=0.024)$ while the 90 -day complication rates did not differ significantly, suggesting that surgical approach could have an impact on early recovery (2). Postoperative complications rate is more likely to be associated with Enhanced Recovery After Surgery (ERAS) program. Indeed, in a recent meta-analysis from 13 studies, ERAS was associated with a significant decrease in postoperative complications rates, length of stay and readmission rates (16). Tan et al. showed that these benefits were significantly linked to ERAS and not minimally invasive surgery (17).

The quest for a decrease in the morbidity of radical cystectomy should continue with a wider implementation of the ERAS program and with the growing trend towards performing intracorporeal urinary diversion. Indeed, it is important to emphasize that, in the CORAL trial, the urinary diversion has been performed extracorporeally and that only 6 patients $(10.2 \%)$ benefited from an orthotopic ileal neobladder. The surgical approach should never penalize the choice of urinary diversion. Thus, if a neobladder is planned, the technique must be mastered, whether one decides to perform the diversion extracorporeally, as is the case in most series, or intracorporeally. By growing their experience in robotic surgery, many surgeons are now able to perform an intracorporeal orthotopic ileal neobladder, which is the next challenging step in robot-assisted radical cystectomy. Brassetti et al. recently reported one of the largest longterm data series on robot-assisted radical cystectomy with totally intracorporeal urinary diversion, mainly orthotopic ileal neobladder (57\%) (18). In this series of 113 patients, neoadjuvant chemotherapy was carried out in $23 \%$ of the cases, an organ-confined disease was observed in $51 \%$ of the cases, and the rate of positive surgical margins was $8 \%$. Longterm oncological outcomes in this series appear similar to the robotic series with extracorporeal diversion (5-year RFS, CSS and OS probabilities of $58 \%, 61 \%$ and $54 \%$, respectively).

In the end, if RARC is gaining ground with good longterm oncological outcomes, there is a need to standardize techniques and future studies should also strive to assess functional outcomes in terms of continence and potency.

\section{Acknowledgments}

Funding: None.

\section{Footnote}

Provenance and Peer Review: This article was commissioned by the editorial office, Translational Andrology and Urology. The article did not undergo external peer review. 
Conflicts of Interest: All authors have completed the ICMJE uniform disclosure form (available at http://dx.doi. org/10.21037/tau-20-873). The authors have no conflicts of interest to declare.

Ethical Statement: The authors are accountable for all aspects of the work in ensuring that questions related to the accuracy or integrity of any part of the work are appropriately investigated and resolved.

Open Access Statement: This is an Open Access article distributed in accordance with the Creative Commons Attribution-NonCommercial-NoDerivs 4.0 International License (CC BY-NC-ND 4.0), which permits the noncommercial replication and distribution of the article with the strict proviso that no changes or edits are made and the original work is properly cited (including links to both the formal publication through the relevant DOI and the license). See: https://creativecommons.org/licenses/by-nc-nd/4.0/.

\section{References}

1. Hussain A, Malik A, Halim MU, et al. The use of robotics in surgery: a review. Int J Clin Pract 2014;68:1376-82.

2. Khan MS, Omar K, Ahmed K, et al. Long-term Oncological Outcomes from an Early Phase Randomised Controlled Three-arm Trial of Open, Robotic, and Laparoscopic Radical Cystectomy (CORAL). Eur Urol 2020;77:110-8.

3. Khan MS, Gan C, Ahmed K, et al. A Single-centre Early Phase Randomised Controlled Three-arm Trial of Open, Robotic, and Laparoscopic Radical Cystectomy (CORAL). Eur Urol 2016;69:613-21.

4. Yuh B, Wilson T, Bochner B, et al. Systematic review and cumulative analysis of oncologic and functional outcomes after robot-assisted radical cystectomy. Eur Urol 2015;67:402-22.

5. Parekh DJ, Messer J, Fitzgerald J, et al. Perioperative outcomes and oncologic efficacy from a pilot prospective randomized clinical trial of open versus robotic assisted radical cystectomy. J Urol 2013;189:474-9.

6. Bochner BH, Dalbagni G, Sjoberg DD, et al. Comparing open radical cystectomy and robot-assisted laparoscopic radical cystectomy: a randomized clinical trial. Eur Urol 2015;67:1042-50.

7. Nix J, Smith A, Kurpad R, et al. Prospective randomized controlled trial of robotic versus open radical cystectomy for bladder cancer: perioperative and pathologic results.
Eur Urol 2010;57:196-201.

8. Parekh DJ, Reis IM, Castle EP, et al. Robot-assisted radical cystectomy versus open radical cystectomy in patients with bladder cancer (RAZOR): an open-label, randomised, phase 3, non-inferiority trial. Lancet 2018;391:2525-36.

9. Bochner BH, Dalbagni G, Marzouk KH, et al. Randomized Trial Comparing Open Radical Cystectomy and Robot-assisted Laparoscopic Radical Cystectomy: Oncologic Outcomes. Eur Urol 2018;74:465-71.

10. Gandaglia G, Karl A, Novara G, et al. Perioperative and oncologic outcomes of robot-assisted vs. open radical cystectomy in bladder cancer patients: A comparison of two high-volume referral centers. Eur J Surg Oncol 2016;42:1736-43.

11. Hanna N, Leow JJ, Sun M, et al. Comparative effectiveness of robot-assisted vs. open radical cystectomy. Urol Oncol 2018;36:88.e1-e9.

12. Li K, Lin T, Fan X, et al. Systematic review and metaanalysis of comparative studies reporting early outcomes after robot-assisted radical cystectomy versus open radical cystectomy. Cancer Treat Rev 2013;39:551-60.

13. Tang K, Xia D, Li H, et al. Robotic vs. open radical cystectomy in bladder cancer: a systematic review and meta-analysis. Eur J Surg Oncol 2014;40:1399-411.

14. Xia L, Wang X, Xu T, et al. Robotic versus open radical cystectomy: an updated systematic review and metaanalysis. PLoS One 2015;10:e0121032.

15. Fonseka T, Ahmed K, Froghi S, et al. Comparing robotic, laparoscopic and open cystectomy: a systematic review and meta-analysis. Arch Ital Urol Androl 2015;87:41-8.

16. Tyson MD, Chang SS. Enhanced Recovery Pathways Versus Standard Care After Cystectomy: A Meta-analysis of the Effect on Perioperative Outcomes. Eur Urol 2016;70:995-1003.

17. Tan WS, Tan MY, Lamb BW, et al. Intracorporeal robotassisted radical cystectomy, together with an enhanced recovery programme, improves postoperative outcomes by aggregating marginal gains. BJU Int 2018;121:632-9.

18. Brassetti A, Cacciamani G, Anceschi U, et al. Long-term oncologic outcomes of robot-assisted radical cystectomy (RARC with totally intracorporeal urinary diversion (ICUD): a multicenter study. World J Urol 2020;38:837-43.

Cite this article as: Pignot G, Treacy P, Walz J. Growing evidence for benefits of minimally invasive radical cystectomy. Transl Androl Urol 2020;9(6):2459-2461. doi: 10.21037/tau-20-873 